\title{
Influence of Starter Culture Ratios and Warm Room Treatment on Free Fatty Acid and Amino Acid in Swiss Cheese
}

\author{
T. Ji, V. B. Alvarez, and W. J. Harper \\ Department of Food Science and Technology \\ The Ohio State University, Columbus 43210
}

\begin{abstract}
Quantification of water-soluble volatile free fatty acids (FFA) and free amino acids (FAA) was performed as a ripening index and an indirect measure of flavor development in Swiss-type cheeses. The objective of this research was to assess the effect of warm room treatment (WRT) and usage ratio of starter cultures, Streptococcus thermophilus and Lactobacillus helveticus vs. propionibacteria, on the concentration of FFA and FAA in pilot plant-scale Swiss cheese. A capillary gas chromatograph equipped with a flame ionization detector was used for the analysis of FFA in Swiss cheese. Free amino acids were analyzed by the Cd-ninhydrin method. Starter culture ratios did not affect development of FAA during the cheese ripening. However, duration of WRT had an effect on the concentration of FAA in the Swiss cheese. Free amino acids increased considerably during WRT. A continuous increase in FAA was shown during 70-d ripening time after WRT. The concentrations of $\mathrm{C}_{2: 0}$ and $\mathrm{C}_{3: 0}$ fatty acids were affected by starter culture ratios after 2-wk WRT, but these differences had mostly disappeared after 3-wk WRT. Similar concentrations of FFA and FAA reported in previous studies were developed in Swiss cheese with a 3-wk WRT and a 0.33:1 ratio of Streptococcus thermophilus and Lactobacillus helveticus to propionibacteria.
\end{abstract}

(Key words: free fatty acid, free amino acid, Swiss cheese, warm room treatment)

Abbreviation key: FAA = free amino acid, FID = flame ionization detector, $\mathbf{G C}=$ gas chromatography, $\mathbf{L A B}=$ lactic acid bacteria, $\mathbf{P A B}=$ propionic acid bacteria, $\mathbf{W R T}=$ warm room treatment.

\section{INTRODUCTION}

Typical Swiss-type cheese has a characteristic nutlike, sweet flavor. The sweet flavor of Swiss cheese has

Received December 1, 2003.

Accepted February 29, 2004.

Corresponding author: V. B. Alvarez; e-mail: alvarez.23@osu.edu. been associated with the water-soluble fraction containing AA (proline and valine) (Hintz et al., 1956). In addition to the amino acids, water-soluble fatty acids, mainly propionic acid (Kosikowski and Mistry, 1997), salt, magnesium ions, calcium ions, tri and tetra peptides, are related to the sweet flavor (Biede and Hammond, 1979). Free amino acids (FAA) also influence the development of cheese flavor through conversion of FAA into a volatile flavor component by amino acid-converting enzymes (Smit et al., 2000). Quantification of FAA in the cheese has been studied previously (Griffith and Hammond, 1989; Baer et al., 1996; Butikofer, 1997; Rychlik and Bosset, 2001, Izco et al., 2002). Free fatty acids produced during cheese ripening act as precursors of distinctive flavor components such as methylketones, alkanes, and aromatic and aliphatic esters in cheeses (Izco and Torre, 2000). Moreover, short-chain $\left(\mathrm{C}_{2: 0}-\mathrm{C}_{6: 0}\right)$ and medium-chain non-branched even carbon-numbered $\left(\mathrm{C}_{8: 0}-\mathrm{C}_{12: 0}\right)$ aliphatic carboxylic acids contribute much of the characteristic aroma in dairy foods ( $\mathrm{Ha}$ and Lindsay, 1990). Volatile FFA and total fatty acids, which are key compounds responsible for cheese flavor, have been quantified in dairy foods by gas chromatography $(\mathbf{G C})$ analysis. Several studies reported that many FFA are flavor contributors of various cheeses. However, the characteristic flavor of Swiss-type cheeses is caused primarily by acetic, propionic, $n$-butyric, isovaleric, and $n$-caproic acids (Ha and Lindsay, 1990; Bosset et al., 1993; Beuvier et al., 1997; Engels et al., 1997; Dirinck and De Winne, 1999; Rychlik and Bosset, 2001).

Thermophilic lactic acid bacteria (LAB), such as Streptococcus thermophilus and Lactobacillus helveticus, and propionic acid bacteria (PAB), mostly Propionibacterium freudenreichii spp. shermanii as a propionic acid and carbon dioxide-forming culture, are common starter cultures in Swiss cheese making. The PAB are unique microorganisms present in Swiss cheese, which start to develop during warm room treatment (WRT) (Polychroniadou, 2001; Kerjean et al., 2000). The PAB are necessary for the development of the characteristic flavor that distinguishes Swiss cheese from other varieties of cheese (Langsurd and Reinbold, 1973). Other changes that take place during WRT of Swiss cheese are the increase of alcohols, esters, sulphur compounds, 
methyl ketones, and 3-methylbutanal and the decrease of other aldehydes (Noel et al., 1999).

The objective of this research was to quantify FFA and FAA during ripening of pilot plant-scale Swiss cheese at different WRT and different starter culture bacterial usage ratio. Thus, changing the starter ratio of thermophilic acid producers to PAB and WRT may modify FAA and FFA production, which, in turn, may possibly affect the development of flavor in Swiss cheese.

\section{MATERIALS AND METHODS}

\section{Swiss Cheese}

Batches of standardized milk (19.5 L) with casein:fat of 0.8:1 were used to make Swiss cheese at the dairy pilot plant at The Ohio State University (Columbus). The cheese was manufactured using the procedures described by Ruiz-Espinosa (2002). Two different thermophilic lactic acid starter cultures, Streptococcus thermophilus (StC-6) and Lactobacillus helveticus (Lh-B01 ), were used in the amounts of 33,66 , and $100 \%$, where $100 \%$ was the supplier-recommended rate $(\mathrm{Chr}$. Hansen, Milwaukee, WI). Propionibacterium freudenreichii spp. Shermanii (PS-1) was added at $100 \%$ to all cheeses; thus, LAB:PAB were 0.33:1, 0.66:1, and 1:1. The recommended usage rates of pelletized frozen cultures per liter of milk were $2.71 \times 10^{-2} \mathrm{~g}$ of StC-6, 1.02 $\times 10^{-2} \mathrm{~g}$ of Lh-B-01, and $5.1 \times 10^{-3} \mathrm{~g}$ of PS- 1 . The milk was set to $33^{\circ} \mathrm{C}$ before inoculation. Double-strength, fermentation-derived chymosin (CHY-MAX; Chr. Hansen, Milwaukee, WI) was added $(0.154 \mathrm{~mL} / \mathrm{L})$ after 30 min of inoculation. The milk was undisturbed to allow coagulation for about $35 \mathrm{~min}$. Curd was then cut and stirred gently for $30 \mathrm{~min}$. About $1.26 \mathrm{~L}$ per vat of distilled water at $48^{\circ} \mathrm{C}$ was added to enhance lactose removal. Temperature was raised $1^{\circ} \mathrm{C} / \mathrm{min}$ up to $48^{\circ} \mathrm{C}$ to cook the curd. Stirring was continued until $\mathrm{pH}$ dropped to 6.45. Curd was scooped into molds under whey to prevent air contact and pressed at $1.96 \mathrm{kPa}$ under whey for $15 \mathrm{~min}$. Whey was drained, and the curd was second pressed at $3.92 \mathrm{kPa}$ for $6 \mathrm{~h}$. The cheese was taken out of the press and covered with cheesecloth to develop to $\mathrm{pH} 5.15$ to 5.25 at room temperature. The cheese was submerged in a $23 \%$ brine solution for $8 \mathrm{~h}$ and then dried for $24 \mathrm{~h}$ at room temperature. The cheese was vacuum packed, held at $10^{\circ} \mathrm{C}$ for a week, and then incubated in a warm room at $25^{\circ} \mathrm{C}$ for 2 and $3 \mathrm{wk}$. The cheeses from the warm room were refrigerated at $4^{\circ} \mathrm{C}$ to stop gas production and held for ripening at $4^{\circ} \mathrm{C}$ for $70 \mathrm{~d}$.

\section{Measurement of FAA}

Analysis of FAA in cheese was performed by the Cdninhydrin method (microplate assay), normally expressed as leucine concentration (Folkertsma and Fox, 1992; Baer et al., 1996). This method is based on the colorimetric reaction of the amino group in AA with ninhydrin in the presence of cadmium salts. The sample solution was prepared in a clear polystyrene microtiter well plate and read at a wavelength of $490 \mathrm{~nm}$ in a microplate reader (Vmax Kinetic microplate reader; Molecular Devices Co., Sunnyvale, CA).

\section{Extraction of FFA}

Water-soluble FFA were extracted by modification of a water extract analysis method reported by Kuchroo and Fox (1982). The extract was prepared in a stomacher bag with $15 \mathrm{~g}$ grated cheese, $30 \mathrm{~mL}$ purified distilled water (US Filter Co., Palm Desert, CA), and 100 $\mu \mathrm{L}$ heptanoic acid (99\%; Aldrich Chemical Co., Inc., Milwaukee, WI) as an internal standard. The samples were mixed for $10 \mathrm{~min}$ in a stomacher (STO-400; Tekmar Co., Cincinnati, $\mathrm{OH}$ ) and held in a water bath at $40^{\circ} \mathrm{C}$ for $1 \mathrm{~h}$. The mixture was centrifuged (Sorvall RC- $5^{+}$; Kendro Laboratory Products, Newtown, CT) at $8^{\circ} \mathrm{C}$ in $50-\mathrm{mL}$ polypropylene screw-capped centrifuge bottles at 10,000 rpm for $30 \mathrm{~min}$. After centrifugation, samples were kept in an icebox for $1 \mathrm{~h}$ to solidify fat. The solid fat pad was broken and filtered through a 2.0- $\mu \mathrm{m}$ glass fiber (Fisher Scientific, Pittsburgh, PA) to remove most of the solidified milk fat. The supernatant was warmed to $25^{\circ} \mathrm{C}$ in a water bath. The $\mathrm{pH}$ of the filtrate was adjusted to 4.6 with $85 \%$ concentrated phosphoric acid (Mallinckrodt, Inc., St. Louis, MO) to precipitate soluble caseins. The acidified supernatant was centrifuged at $12,000 \mathrm{rpm}$ for $30 \mathrm{~min}$ at $5^{\circ} \mathrm{C}$ in a screwcapped centrifuge bottle. After centrifugation, the acidified supernatant was filtered through a $0.4-\mu \mathrm{m}$ filter. The samples were refrigerated overnight to precipitate the small particles of soluble caseins and to solidify the fat. The next day, the cheese extracts were filtered through $0.2-\mu \mathrm{m}$ syringe filters to remove clotted casein and fat particles before GC injection.

\section{GC Analytical Conditions}

A capillary gas chromatograph (HP 6890A; Agilent Technologies, Inc., Wilmington, DE) equipped with a flame ionization detector (FID) was used for the quantitative analysis of water-soluble volatile FFA in Swiss cheese. Swiss cheese water extract $(0.2 \mu \mathrm{L})$ was injected by an auto injector (HP 7683 series). The injection port was packed with glass wool and held at $220^{\circ} \mathrm{C}$. The FID was set at $270^{\circ} \mathrm{C}$. The oven temperature was held at 


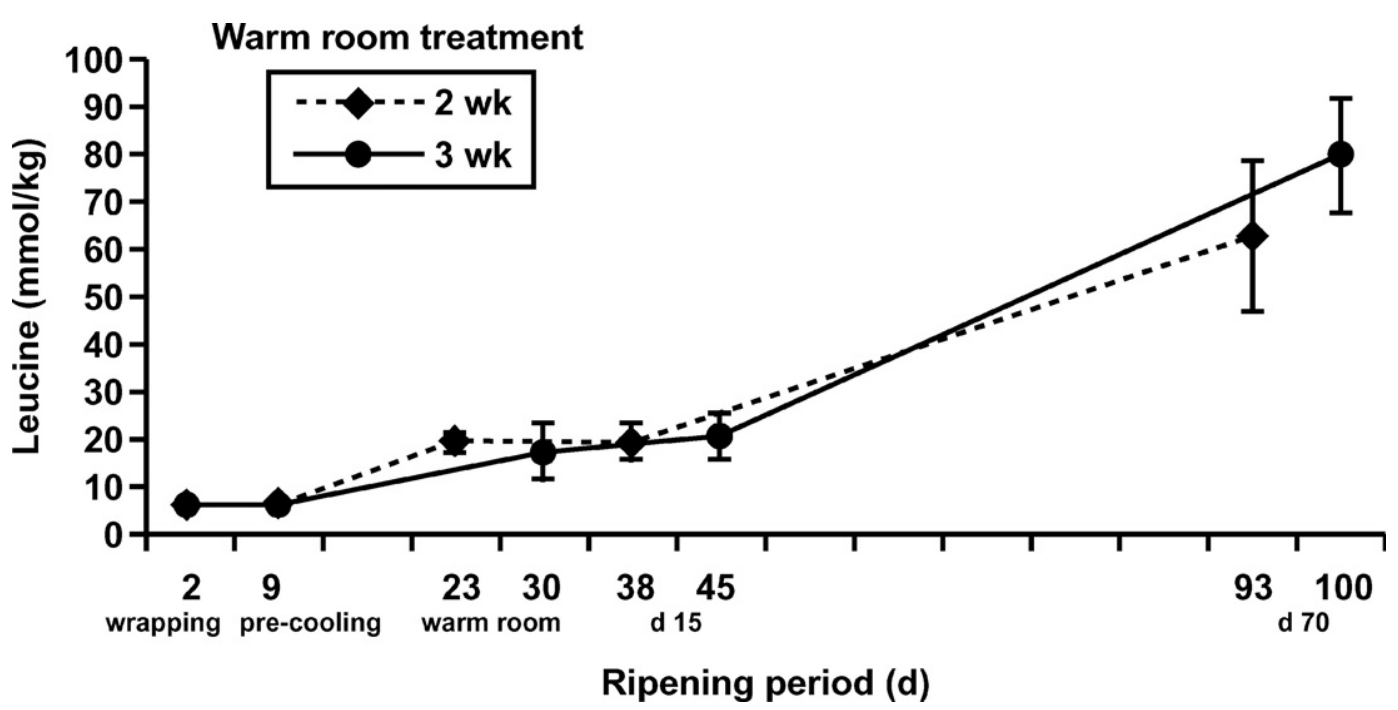

Figure 1. Comparison of total free amino acids in pilot plant-scale Swiss cheese with different warm room treatments. (Average of all cheeses).

$110^{\circ} \mathrm{C}$ for $1 \mathrm{~min}$ after the injection and increased $10^{\circ} \mathrm{C} /$ min until a maximum temperature of $230^{\circ} \mathrm{C}$ was obtained. The carrier gas pressure was held at $82.7 \mathrm{kPa}$ consistently. A 25-m length column (HP-FFAP) with a $0.32-\mathrm{mm}$ internal diameter and 0.52-m film thickness was used for the FFA analysis. The column was heated to $238^{\circ} \mathrm{C}$ for $11 \mathrm{~min}$ to purge the column of volatile compounds and recondition it for subsequent injection. The GC was operated in a split injection mode with a split ratio of $1: 1$. The carrier gas used was $99.99 \%$ pure helium. The carrier gas velocity was $44.8 \mathrm{~cm} / \mathrm{s}$. The split flow was $2.73 \mathrm{~mL} / \mathrm{min}$. Chromatograms were integrated with HP Chemstation data analysis software. Quantification of short-chain FFA $\left(\mathrm{C}_{2: 0}-\mathrm{C}_{6: 0}\right)$ was performed by comparing the peak area with that of an internal standard and by employing linear regression curves prepared from authentic fatty acids (Sigma-Aldrich Co., St. Louis, MO). Medium-chain FFA with even carbon number $\left(\mathrm{C}_{8: 0}-\mathrm{C}_{12: 0}\right)$ were identified, but not quantified because of portioning in both aqueous and lipid phases.

\section{Statistical Analysis}

Experiments were performed according to a nested factorial design with repeated measurements (number of sampling times). The independent variables were starter culture usage ratios of LAB to PAB (0.33:1, 0.66:1, and 1:1) and WRT times (2 and $3 \mathrm{wk}$ ). Four replications were performed for cheese making. The data were subjected to ANOVA using the general linear model of SAS (1999). Tukey's multiple comparisons were carried out to compare pairs of treatment means. The statistical significance was determined at $P<0.05$.

\section{RESULTS AND DISCUSSION}

The overall composition of cheese was $38 \%$ moisture, $47 \%$ milkfat (dry basis), and $27 \%$ protein. The composition was within the US requirements for the standardized Swiss cheese of a minimum $43 \%$ milkfat by weight of the solids and a maximum of $41 \%$ moisture (FDA, 2003). Culture ratios used in cheese making did not affect the composition (data not shown). Average $\mathrm{pH}$ of cheeses before WRT with LAB to PAB ratios of $0.33: 1$, $0.66: 1$, and $1: 1$ were $5.18,5.13$, and 5.11, respectively. Extended WRT time increased $\mathrm{pH}$, and a higher culture ratio lowered $\mathrm{pH}$ as expected. The mean $\mathrm{pH}$ values of cheese samples were 5.31 and 5.51 at the end of 2- and 3wk WRT, respectively. A recent study in our laboratory showed that the development of FAA in Swiss-type cheese during ripening was associated with the increased pH (Ruiz-Espinosa, 2002).

\section{FAA}

Culture ratio had no effect on the FAA levels at any point during manufacture, WRT, and subsequent ripening (data not shown). The warm room holding time significantly affected $(P<0.05)$ FAA concentration at the end of the ripening (70 d after WRT) (Figure 1). The total FAA increased (ca. 27\%) from $62.31 \mathrm{mmol} / \mathrm{kg}$ with 2 -wk WRT to $79.34 \mathrm{mmol} / \mathrm{kg}$ with 3 -wk WRT. The latter FAA concentration is similar to that found in Emmental cheese ripened for $80 \mathrm{~d}$ (Baer et al., 1996). The increase in FAA observed may be associated with the exponential increase in numbers of $\mathrm{PAB}$ that prefer peptides for growth (Baer, 1995; Gagnaire et al., 2001). 

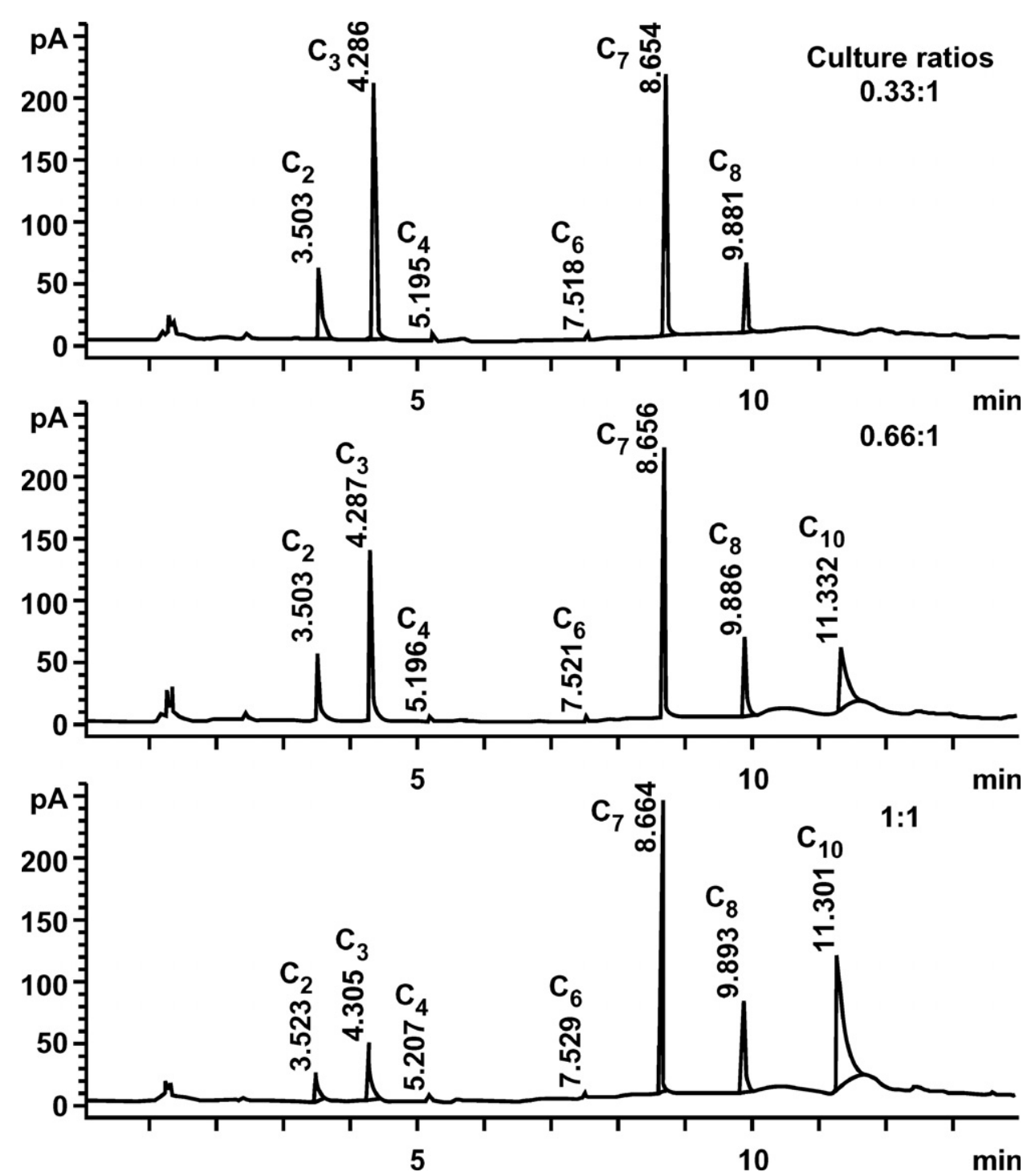

Figure 2. Gas chromatogram of volatile water-soluble free fatty acids in 70-d ripened Swiss cheese after 2-wk warm room treatment. Culture ratio = lactic acid bacteria:propionic acid bacteria. $\mathrm{C}_{7}$ (heptanoic acid) $=$ International Standard.

Another possible explanation is the increase in production of proteinases and peptidases by either LAB or non-starter LAB activity. Lactic acid bacteria possess a comprehensive proteolytic system that is able to hydrolyze oligopeptides to small peptides and amino acids (Sousa et al., 2001). Grappin et al. (1999) reported that the concentrations of FAA in Swiss-type cheeses could be different depending on the activity of peptidase and cell wall proteinase of LAB. It also has been found that the presence of non-starter LAB contributes to the production of FAA because of increased peptidase activity in cheese (Ardo and Pettersson, 1988; Peterson et al., 1990). There are other factors not investigated in the present study, such as water activity, lactic acid concentration, $\mathrm{pH}, \mathrm{NaCl}$ concentration, and copper content, which can also affect the formation of FAA (Steffen et al., 1993). Differences in the ratios of LAB to PAB had no significant $(P>0.05)$ influence upon the development of FAA during the entire ripening period (data not shown).

\section{FFA}

Detected FFA were acetic $\left(\mathrm{C}_{2: 0}\right)$, propionic $\left(\mathrm{C}_{3: 0}\right), n$ butyric $\left(\mathrm{C}_{4: 0}\right)$, isovaleric $\left(i-\mathrm{C}_{5: 0}\right), n$-caproic $\left(\mathrm{C}_{6: 0}\right), n$-caprylic $\left(\mathrm{C}_{8: 0}\right)$, $n$-capric $\left(\mathrm{C}_{10: 0}\right)$, and $n$-lauric $\left(\mathrm{C}_{12: 0}\right)$ acids. Figure 2 is an example of the FFA profile for 70-d ripened cheese after 2 -wk WRT. The chromatogram shows that the FFA were eluted according to carbon chain length. It also shows the difference of peak area in 


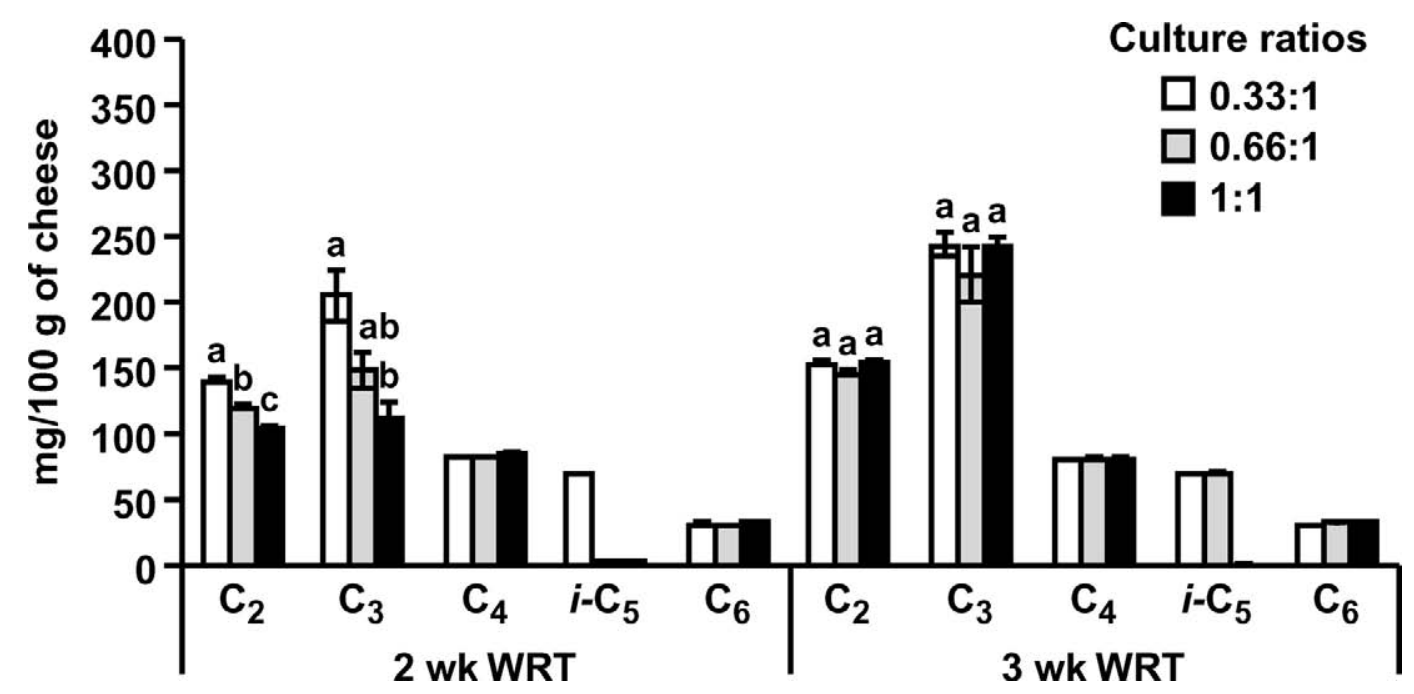

Figure 3. Concentration of short-chain free fatty acids in a pilot plant-scale Swiss cheese at 15-d ripening after warm room treatment $\left(\right.$ WRT). Culture ratio = lactic acid bacteria:propionic acid bacteria. ${ }^{\mathrm{a}, \mathrm{b}}$ Means with the same superscripts within the same category did not differ $(P>0.05)$.

accordance with culture usage ratios. Only $\mathrm{C}_{2: 0}, \mathrm{C}_{3: 0}$, and $\mathrm{C}_{10: 0}$ concentrations were affected by the culture ratio in the chromatogram.

Concentrations ( $\mathrm{mg} / 100 \mathrm{~g}$ of cheese) of short-chain FFA $\left(\mathrm{C}_{2: 0}-\mathrm{C}_{6: 0}\right)$ in the Swiss cheese for 15 -d and $70-\mathrm{d}$ ripened cheeses after WRT are shown in Figures 3 and 4. The most predominant FFA was propionic acid $\left(\mathrm{C}_{3: 0}\right)$ during the cheese ripening time, regardless of starter culture ratios and WRT. The concentrations of $\mathrm{C}_{2: 0}$ and $\mathrm{C}_{3: 0}$ were higher in 3 -wk warm room treated cheese than the 2 -wk treated cheese $(P<0.05)$; however, $\mathrm{C}_{4: 0}$ and $\mathrm{C}_{6: 0}$ did not change significantly. The starter culture ratio affected significantly the concentration of $\mathrm{C}_{2: 0}$ and $\mathrm{C}_{3: 0}$ in 2-wk WRT only (Figures 3 and 4). There was a decrease of $\mathrm{C}_{2: 0}$ and $\mathrm{C}_{3: 0}$ as a result of the increase of starter culture ratios. The decrease may be caused by the slow growth of $\mathrm{PAB}$, which limits the propionic fermentation of lactic acid with 2 -wk WRT. It has been reported that $\mathrm{LAB}$ activities influence the growth of PAB (Noel et al., 1999). Previous studies reported that $\mathrm{LAB}$ and $\mathrm{PAB}$ interactions are very complex and cannot be explained by only one factor (Thierry et al., 1998;

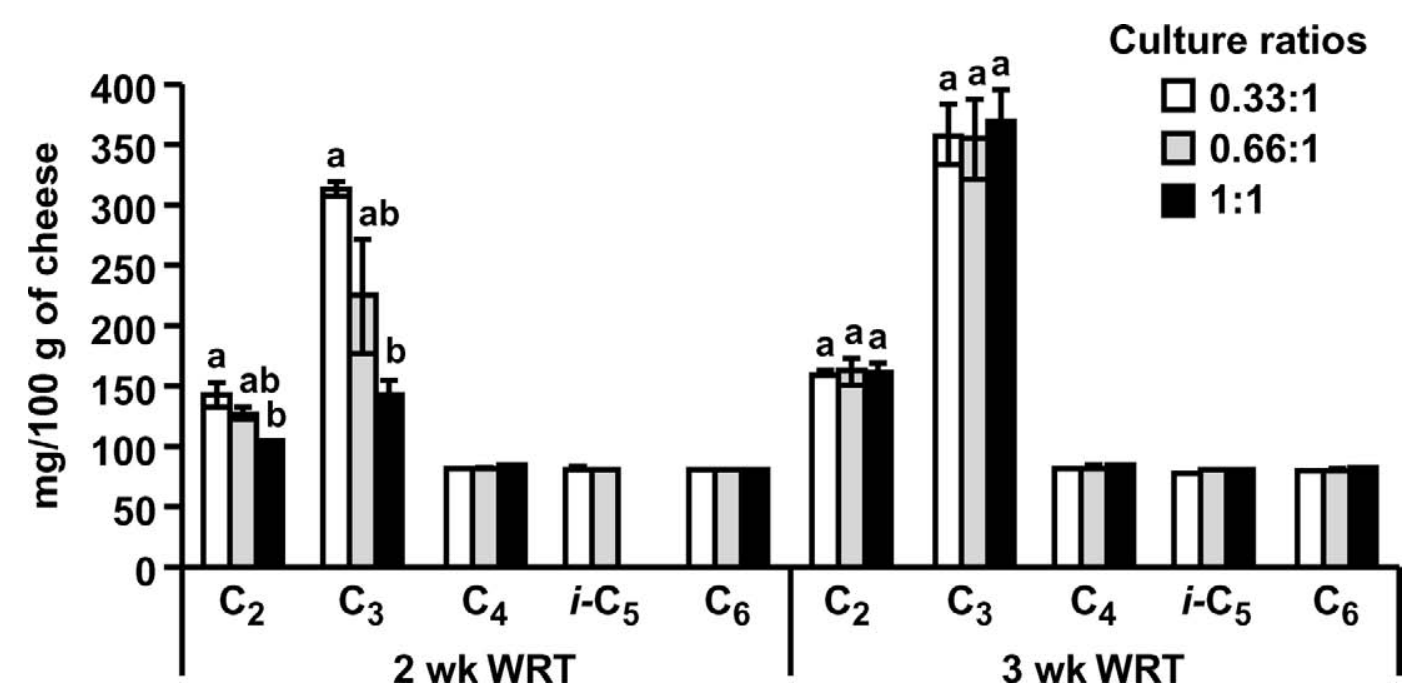

Figure 4. Concentration of short-chain free fatty acids in a pilot plant-scale Swiss cheese at 70-d ripening after warm room treatment $(\mathrm{WRT})$. Culture ratio = lactic acid bacteria:propionic acid bacteria. ${ }^{\mathrm{a}, \mathrm{b}}$ Means with the same superscripts within the same category did not differ $(P>0.05)$. 
Grappin et al., 1999). Acetic acid production is stoichiometrically related to that of $\mathrm{C}_{3: 0}$ and carbon dioxide in the ratios 1:2:1 by the propionic fermentation of lactic acid (Bosset et al., 1993). The volatile $\mathrm{C}_{2: 0}$ can be produced by oxidative deamination of glycine, alanine, and serine. These reactions produce substances that can act as aroma precursors, mainly through deamination, transamination, and decarboxylation as mentioned earlier. The main origin of $\mathrm{C}_{3: 0}$ is certainly propionic fermentation (propionibacteria) as mentioned in the discussion of the origin of $\mathrm{C}_{2: 0}$. The high concentration of $\mathrm{C}_{3: 0}$ in Swiss cheese produced by the action of $\mathrm{PAB}$ results in a sweet flavor (Steffen et al., 1993). Thus, both $\mathrm{C}_{2: 0}$ and $\mathrm{C}_{3: 0}$ are important components of the Swiss cheese flavor profile. The concentration of $\mathrm{C}_{4: 0}$ was consistent in all cheeses (Figures 3 and 4). There were no differences among the treatments. The butyric fermentation of lactose produced $\mathrm{C}_{4: 0}$ mainly and is undesirable for flavor development (Steffen et al., 1993). Other possible sources of FFA with $\geq 4$ carbons are lipolysis and the breakdown of some amino acids through metabolic pathway (Urbach, 1993). Typical FFA of Swiss cheese are $\mathrm{C}_{3: 0}, \mathrm{C}_{4: 0}$, and $i$ - $\mathrm{C}_{5: 0}$ (Dirinck and De Winne, 1999). Low concentrations of branched butyric acid, 3-methylbutanoic ( $i$ - $\mathrm{C}_{5: 0}$ ), were detected (70 to 80 $\mathrm{mg} / 100 \mathrm{~g}$ ) in the cheeses (Figures 3 and 4). Data show that $i$ - $\mathrm{C}_{5: 0}$ developed completely in short ripening time with the least amount of starter cultures. These results suggest that WRT and culture ratios influenced the formation of $i-\mathrm{C}_{5: 0}$ because of proteolysis and degradation of the amino acid, leucine, and valine as reported in other studies (Nakae and Elliott, 1965; Molimard and Spinnler, 1996). Caproic acid $\left(\mathrm{C}_{6: 0}\right)$ increased significantly from ca. 31 to $81 \mathrm{mg} / 100 \mathrm{~g}$ of cheese with increasing ripening time from 15 to $70 \mathrm{~d}$ after WRT, respectively. However, the length of WRT and different culture ratios did not affect $\mathrm{C}_{6: 0}$ formation. This result can be explained by findings of Dirinck and De Winne (1999) who reported that $\mathrm{C}_{6: 0}$ was formed mainly from lipid degradation.

\section{CONCLUSION}

Different starter culture ratios affected only the development of FFA in pilot plant-scale Swiss cheese. However, WRT influenced the development of both FFA and amino acids. It was possible to develop similar concentrations of acetic, propionic, and FAA in the Swiss cheese using a 0.33:1 ratio of Streptococcus thermophilus and Lactobacillus helveticus to propionibacteria compared with a 1:1 ratio of the cultures. To develop enough FFA and amino acids that are required for a typical Swiss cheese flavor, it was necessary to keep the cheese in the warm room for $3 \mathrm{wk}$.

\section{REFERENCES}

Ardo, Y., and H. E. Pettersson. 1988. Accelerated cheese ripening with heat treated cells of Lactobacillus helveticus and a commercial proteolytic enzyme. J. Dairy Res. 55:239-245.

Baer, A. 1995. Influence of casein proteolysis by starter bacteria, rennet and plasmin on the growth of propionibacteria in Swisstype cheese. Lait 75:391-400.

Baer, A., I. Ryba, J. Meyer, and U. Butikofer. 1996. Microplate assay of free amino acids in cheeses. Lebensm. Wiss. U. Technol. 29:58-62.

Beuvier, E., K. Berthaud, S. Cegarra, A. Dasen, S. Pochet, S. Buchin, and G. Duboz. 1997. Ripening and quality of Swiss-type cheese made from raw, pasteurized or microfiltered milk. Int. Dairy J. 7:311-323.

Biede, S. L., and E. G. Hammond. 1979. Swiss cheese flavor: II. Organoleptic analysis. J. Dairy Sci. 62:238-248.

Bosset, J. O., M. Collomb, and R. Sieber. 1993. The aroma composition of Swiss Gruyere cheese. IV. The acidic volatile components and their changes in content during ripening. Lebensm. Wiss. U. Technol. 26:581-592.

Butikofer, D. F. 1997. Development of free amino acids in Appenzeller, Emmentaler, Gruyere, Raclette, Sbrinz and Tilsiter cheese. Lait 77:91-100.

Dirinck, P., and A. De Winne. 1999. Flavor characterization and classification of cheeses by gas chromatographic-mass spectrometric profiling. J. Chromatogr. A 847:203-208.

Engels, W. J. M., R. Dekker, C. de Jong, R. Neeter, and S. Visser. 1997. A comparative study of volatile compounds in the watersoluble fraction of various types of ripened cheese. Int. Dairy J. 7:255-263.

FDA. 2003. Cheeses and Related Products: Swiss and Emmentaler Cheese. Code of Federal Regulations 21:133.195. U.S. Government Printing Office, Washington, DC.

Folkertsma, B., and P. F. Fox. 1992. Use of Cd-ninhydrin reagent to assess proteolysis in cheese during ripening. J. Dairy Res. $59: 217-224$

Gagnaire, V., A. Thierry, and J. Leonil. 2001. Propionibacteria and facultatively heterofermentative lactobacilli weakly contribute to secondary proteolysis of Emmental cheese. Lait 81:339-353.

Grappin, R., E. Beuvier, Y. Bouton, and S. Pochet. 1999. Advances in the biochemistry and microbiology of Swiss-type cheeses. Lait 79:3-22.

Griffith, R., and E. G. Hammond. 1989. Generation of Swiss cheese flavor components by reaction of amino acids with carbonyl components. J. Dairy Sci. 72:604-613.

Ha, J. K., and R. C. Lindsay. 1990. Method for the quantitative analysis of volatile free and total branched-chain fatty acids in cheese and milk fat. J. Dairy Sci. 73:1988-1999.

Hintz, P. C., W. L. Slater, and W. J. Harper. 1956. A survey of various free amino acids and fatty acids in domestic Swiss cheese. J. Dairy Sci. 39:235-244

Izco, J. M., and P. Torre. 2000. Characterization of volatile flavor compounds in Roncal cheese extracted by the 'purge and trap' method and analyzed by GC-MS. Food Chem. 70:409-417.

Izco, J. M., M. Tormo, and R. Jiménez-Flores. 2002. Rapid simultaneous determination of organic acids, free amino acids, and lactose in cheese by capillary electrophoresis. J. Dairy Sci. 85:2122-2129.

Kerjean, J. R., S. Condon, R. Lodi, G. Kalantzopoulos, J. F. Chamba, T. Suomalainen, T. Cogan, and D. Moreau. 2000. Improving the quality of European hard-cheeses by controlling of interactions between lactic acid bacteria and propionibacteria. Food Res. Int. 33:281-287.

Kosikowski, F. V., and V. V. Mistry. 1997. Cheese and Fermented Milk Foods. Vol. I. Origins and Principles. 3rd ed. F. V. Kosikowski, LLC, Westport, CT.

Kuchroo, C. N., and P. F. Fox. 1982. Soluble nitrogen in Cheddar cheese: Comparison of extraction procedures. Milchwissenschaft 37:331-335.

Langsurd, T., and G. W. Reinbold. 1973. Flavor development and microbiology of Swiss-cheese - A review. III. Ripening and flavor production. J. Milk Food Technol. 36:593-609. 
Molimard, P., and H. E. Spinnler. 1996. Review: Compounds involved in the flavor of surface mould-ripened cheese: Origins and properties. J. Dairy Sci. 79:169-184.

Nakae, T., and J. A. Elliott. 1965. Production of volatile fatty acids by some lactic acid bacteria. II. Selective formation of volatile fatty acids by degradation of amino acids. J. Dairy Sci. 48:293-299.

Noel, Y., P. Boyaval, A. Thierry, V. Gagnaire, and R. Grappin. 1999. Eye formation and Swiss-type cheeses. Pages 222-250 in Technology of Cheese Making. B. A. Law, ed. CRC Press LLC, Boca Raton, FL.

Peterson, S. D., R. T. Marshall, and H. Heyman. 1990. Peptidase profiling of lactobacilli associated with Cheddar cheese and its application to identification and selection of strains for cheese ripening studies. J. Dairy Sci. 73:1454-1464.

Polychroniadou, A. 2001. Eye's in cheese: A concise review. Michwissenschaft 56:74-77.

Ruiz-Espinosa, H. 2002. Starter culture addition rate and ripening time in small-scale rindless Swiss Cheese manufacture. M.S. Thesis, The Ohio State University, Columbus.
Rychlik, M., and J. O. Bosset. 2001. Flavor and off-flavor compounds of Swiss Gruyere cheese. Identification of key odorants by quantitative instrumental and sensory studies. Int. Dairy J. 11:903-910.

SAS User's Guide: Statistics, Version 8.1 Edition. 1999. SAS Inst., Inc., Cary, NC.

Smit, G., A. Verheul, R. van Kranenburg, E. Ayad, R. Siezen, and W. Engels. 2000. Cheese flavour development by enzymatic conversions of peptides and amino acids. Food Res. Int. 33:153-160.

Sousa, M. J., Y. Ardö, and P. L. H. McSweeney. 2001. Advances in the study of proteolysis during cheese ripening. Int. Dairy J. 11:327-345.

Steffen, C., P. Eberhard, J. O. Bosset, and M. Ruegg. 1993. Swisstype varieties. Pages $83-110$ in Cheese: Chemistry, Physics and Microbiology. Vol. 2. P. F. Fox, ed. Chapman \& Hall, London, UK.

Thierry, A., D. Salvat-Branaud, M. N. Madec, F. Michel, and J. L. Maubois. 1998. Swiss cheese ripening: Dynamics of bacterial populations and changes in the composition of the aqueous phase. Lait 78:521-542.

Urbach, G. 1993. Relations between cheese flavor and chemical composition. Int. Dairy J. 3:389-422. 